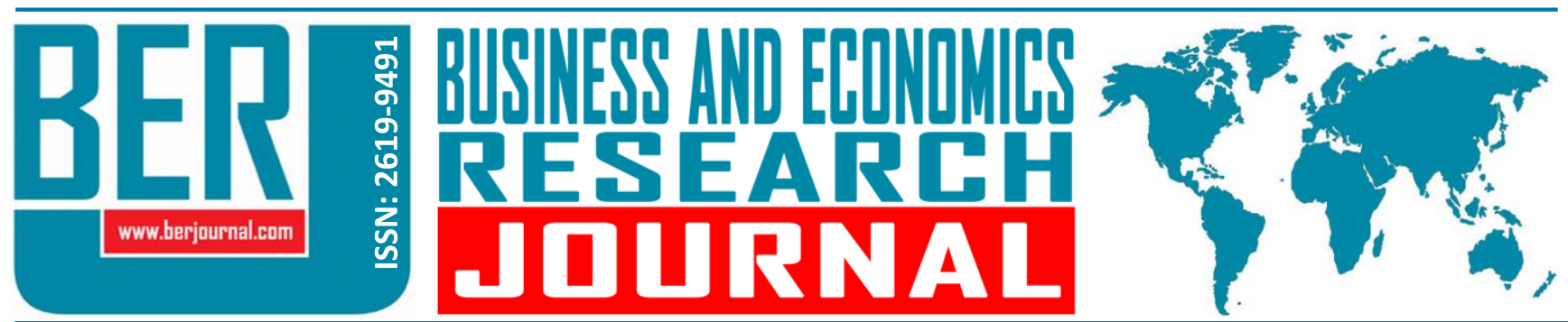

Business and Economics Research Journal Vol. 10, No. 3 Special Issue, 2019, pp. 617-628 doi: 10.20409/berj.2019.189

\title{
Finansal Gelişme ve Büyüme İlişkisi: Türkiye için Bootstrap Nedensellik Analizi*
}

\author{
Selim Demez ${ }^{\mathrm{a}}$, Oktay Kizilkaya ${ }^{\mathrm{b}}$, Mehmet Dag $^{\mathrm{c}}$
}

Öz: Küreselleşen dünya ekonomisinde finansal gelişmenin ekonomik büyüme üzerindeki etkisi iktisat literatüründe üzerinde oldukça fazla çalışılan bir konudur. Konu hakkındaki teorik ve ampirik çalışmalar genellikle gelişmiş bir finansal sistemin piyasalara işlevsellik kazandırarak ekonomik büyümeyi artıracağını ya da ekonomik büyümenin finansal sistemin gelişimini beraberinde getireceğini ortaya koymaktadır. Bu iki görüşün yanı sıra az da olsa literatürde finansal gelişme ile ekonomik büyüme arasında herhangi bir ilişkinin olmadığını savunan yaklaşımlarda yer almaktadır. Ayrıca finansal gelişme ile ekonomik büyüme arasındaki ilişkiyi inceleyen ampirik çalışmalarda finansal gelişmeyi temsilen alınan değiş̧enlerin, analiz dönemlerinin ve kullanılan ekonometrik yöntemin ilişki hakkında farklı sonuçlara sebep olduğunu belirtmek gerekmektedir. Bu çalışmada 2006Q1-2018Q2 dönemi üç aylık veriler kullanılarak Türkiye'deki finansal gelişme ile büyüme ilişkisi Hacker ve Hatemi-J (2012) Bootstrap nedensellik testi ile incelenmiştir. Finansal gelişmişliği temsilen alınan değişkenlerden sadece toplam yurtiçi kredilerden büyümeye doğru tek yönlü nedensellik ilişkisi elde edilmiştir. Elde edilen bu sonuç Türkiye ekonomisinde arz öncüllü (supply-leading) hipotezin geçerli olduğunu göstermektedir.

Anahtar Sözcükler: Finansal Gelişme, Bootstrap Nedensellik, Büyüme

JEL: C32, 016, G10

$\begin{array}{ll}\text { Geliş } & : \text { 26 Ocak } 2019 \\ \text { Düzeltme } & : 12 \text { Şubat } 2019 \\ \text { Kabul } & : 23 \text { Şubat } 2019 \\ \text { Tür } & \text { : Araştırma }\end{array}$

\section{Relationship Between Financial Development and Growth: Bootstrap Causality Analysis for Turkey}

\footnotetext{
Abstract: The impact of financial development on economic growth in the globalized world economy is a much-emphasized issue in the economic literature. The theoretical and empirical studies on the subject generally reveal that an advanced financial system will increase the economic growth by providing functionality to the markets or that economic growth will bring about the development of the financial system. In addition to these two perspectives, in the literature, there are few approaches suggest that there is no relationship between financial development and economic growth. Also, empirical studies examining the relationship between financial development and economic growth require different results regarding the relationship between variables, analysis periods and the econometric method used. In this study, the relationship between financial development and economic growth in Turkey was examined by Hacker and Hatemi-J (2012) bootstrap causality test using quarterly data 2006Q1-2018Q2 period. From total domestic loans that variables are taken to represent financial development, only oneway causality to economic growth was found. These results indicate that supply-leading hypothesis is valid in Turkey.
}

Keywords: Financial Development, Bootstrap Causality, Growth

JEL: C32, 016, G10
Received : 26 January 2019

Revised : 12 February 2019

Accepted : 23 February 2019

Type : Research

Cite this article as: Demez, S., Kizilkaya, O., \& Dag, M. (2019). Finansal gelişme ve büyüme ilişkisi: Türkiye için Bootstrap nedensellik analizi. Business and Economics Research Journal, 10(3 Special Issue), 617-628.

The current issue and archive of this Journal is available at: www.berjournal.com

a Asst. Prof., PhD., Hakkari University, Faculty of Economics and Administrative Sciences, Department of Economics, Hakkari, Turkiye, selimdemez@hakkari.edu.tr (ORCID ID: 0000-0001-6885-0499)

b Asst. Prof., PhD., Hakkari University, Faculty of Economics and Administrative Sciences, Department of Economics, Hakkari, Turkiye, oktaykizilkaya@hakkari.edu.tr (ORCID ID: 0000-0002-3412-561)

Asst. Prof., PhD., Siirt University, Faculty of Economics and Administrative Sciences, Department of Public Finance, Siirt, Turkiye, mehmetdag323@gmail.com (ORCID ID: 0000-0003-2206-2184) 


\section{Giriş}

Küreselleşen dünyada yüksek büyüme rakamlarına ulaşabilmek özellikle yeterli sermaye birikimine sahip olmayan ülkeler açısından büyük öneme sahiptir. Finansal sistem fon arz edenlerle fon talep edenlerin bir araya geldikleri piyasadır. Yeni finansal kurumlar, ürünler, aracılık hizmetlerinin gelişmesi ve teknolojik gelişmeler finansal sistemin gelişmesini sağlamaktadır. Bu durum fon arz ve talebinde artış anlamına gelir. Finansal sistemin, ticaretin geliştirilmesi, riskin dağıtılması ve azaltılması (hedging), portföy çeşitlendirilmesi, yöneticilerin izlenmesi, denetim ve tasarrufların harekete geçirilmesi gibi özellikleri de finansal gelişmeye katkı sağlamaktadır. Finansal piyasalar ve kurumların ortaya çıkmasının temel nedeni ise yatırımcıların bilgi ve işlem maliyetlerine katlanmak istememeleridir (Levine, 1999: 691). Böyle bir durumda elbette ki fon ihtiyacı olan yatırımcılar intiyaç duydukları sermayeye daha uygun ve düşük maliyetlerle ulaşabilme imkanına kavuşmuş olacaklardır. Eğer bu yatırımlardan beklenen getiri sağlanabilmişse bu etkinin büyüme rakamlarına yansıması kaçınılmazdır.

Finansal gelişme dar anlamda bir ekonomideki finansal ürünlerin sayısının ve kullanımının artmasıdır. Geniş anlamda kurumların, ürünlerin, finansal aracıların ve aracılık hizmetlerinin kısaca finansal piyasaların gelişimini ifade etmektedir. Finansal varlıklar, hizmetler ve kurumlardaki kişi başına düşen artış ise finansal derinleşme olarak ifade edilmektedir (Öztürk Darıcı ve Keskinoğlu, 2011: 55). Finansal gelişme ve derinleşme ile birlikte artan fonlar reel sektöre aktarıldığında ekonomik büyüme artmaktadır.

Robinson (1952) ekonomik büyümenin bir sonucu olarak finansal hizmet talebi artırmakta ve bur durumun ekonomik büyümeyi tetiklediğini belirtmiştir (Robinson, 1952: 86). Schumpeter (1911) ve Goldsmith (1969) yatırım projeleri arasından iyi seçim yapılmasında toplam faktör verimliliği ve faktör birikiminin önemine dikkat çekerek. Finansal hizmetlerin ve kurumların kalitesi ile ülkeler arasındaki gelişmişlik farklarının kısmen açıklanabileceğini ileri sürmüşlerdir (Fung, 2009: 57).

McKinnon (1973) ve Shaw (1973) çalışmalarında devletin özellikle bankacılık sistemine uyguladığı yasal kısıtlamaların finansal gelişmeyi negatif etkilediği ve bunun sonucunda ekonomik büyümenin azaldığı yönündeki hipotezleri, finansal gelişme ekonomik büyüme ilişkisinin temelini oluşturmaktadır. Bu önermenin benzeri modern büyüme teorilerinde finansal aracılığın ekonomik büyümeyi artırdığı şeklinde yer almaktadır (Demetriades ve Dussein, 1996: 388).

Patrick (1966) finansal gelişme ile ekonomik büyüme ilişkisinin yönüne göre 'arz öncüllü' ve 'talep takipli' iki durumun gerçekleşebileceğini ortaya koymuştur. Talep takipli denilen durum finansal gelişmenin ekonomik büyümenin sonucunda meydana geldiğini, diğer bir ifadeyle finansal gelişme yatırımcılar ve tasarruf sahiplerinin finansal varlık ve hizmetlere yönelik talebinin sonucudur. Arz öncüllü ilişki ise tersi durumu ifade etmekte yani finansal birimlerin yatırımcıların taleplerine yönelik gelişerek ekonomik büyümeyi etkilediğini öne sürmektedir. (Patric, 1966: 174-175).

Fung (2009) ise finansal gelişme ile büyüme arasındaki yakınsamayı test etmiştir. Orta ve yüksek gelirli ülkelerde ekonomik büyüme ve finansal gelişme için koşullu yakınsamanın geçerli olduğunu ve finansal gelişme ile ekonomik büyüme arasındaki ilişkinin kalkınmanın ilk aşamasında daha güçlü olduğunu ve büyüme sürdükçe giderek azaldığını belirtmiştir. Bu durum aynı yüksek ve düşük gelirli ülkeler arasındaki farkı da ortaya koymaktadır. Aynı zamanda teknoloji transferi ile finansal gelişme arasında kalkınmanın ilk evresinde pozitif bir ilişki olduğunu belirterek belirli bir finansal gelişmişlik düzeyinden sonra bu ilişkinin giderek azalacağını belirtmiştir (Fung, 2009: 64-65).

\section{Seçilmiş Literatür}

Konu ile ilgili oldukça fazla çalışma yer aldığından Tablo 1'de seçilmiş ampirik literatüre yer verilmiştir. Çalışmaların tamamı farklı ülke ya da ülke grupları için panel veri ve zaman serisi analiz yöntemlerini kullanarak finansal gelişme ile ekonomik büyüme ilişkisini ve/veya yönünü tespit etmeye yöneliktir. Finansal gelişme ve ekonomik büyümeyi temsilen alınan değişkenler bu çalışmada kullanılanlarla aynıdır. 
S. Demez - O. Kizilkaya - M. Dag

Tablo 1. Ampirik Literatür Özeti

\begin{tabular}{|c|c|c|c|}
\hline Yazar(lar) & Ülke(ler)-Dönem & Ekonometrik Yöntem & Sonuçlar \\
\hline $\begin{array}{l}\text { Demetriades ve } \\
\text { Luintel (1996) }\end{array}$ & $\begin{array}{l}\text { Hindistan } \\
\text { 1961-1991 }\end{array}$ & Zaman serisi analizi & $\begin{array}{l}\text { Finansal derinlik ile büyüme arasında çift } \\
\text { yönlü bir nedensellik ilişkisi bulunduğunu } \\
\text { ortaya koymuşlardır. }\end{array}$ \\
\hline $\begin{array}{l}\text { Arestis ve } \\
\text { Demetriades (1997) }\end{array}$ & $\begin{array}{l}\text { Almanya } \\
\text { 1979Q2-1991Q4, } \\
\text { Amerika } \\
\text { 1979Q4-1991Q4, } \\
\text { Güney Kore } \\
\text { 1956-1994 }\end{array}$ & $\begin{array}{l}\text { Johansen eşbütünleşme } \\
\text { analizi }\end{array}$ & $\begin{array}{l}\text { Analize konu olan üç ülke içinde finansal } \\
\text { gelişme ve ekonomik büyüme arasında uzun } \\
\text { dönemli bir ilişki bulunmuştur. }\end{array}$ \\
\hline Akinboade (1998) & $\begin{array}{l}\text { Botsvana } \\
1972-1995\end{array}$ & $\begin{array}{l}\text { Granger nedensellik } \\
\text { analizi }\end{array}$ & $\begin{array}{l}\text { Finansal gelişme ile büyüme arasındaki çift } \\
\text { yönlü nedensellik olduğunu belirtmiştir. }\end{array}$ \\
\hline Gahali (1999) & $\begin{array}{l}\text { Tunus } \\
1963-1993\end{array}$ & $\begin{array}{l}\text { Johansen eşbütünleşme } \\
\text { ve Granger nedensellik } \\
\text { analizi }\end{array}$ & $\begin{array}{l}\text { Finansal gelişme ile büyüme arasında } \\
\text { eşbütünleşme ilişkisinin olduğu belirtilerek } \\
\text { finansal gelişmeden büyümeye doğru } \\
\text { nedensellik ilişkisinin var olduğu sonucuna } \\
\text { varılmıştır. }\end{array}$ \\
\hline Ram (1999) & $\begin{array}{l}95 \text { ülke } \\
1963-1988\end{array}$ & Regresyon analizi & $\begin{array}{l}\text { Finansal gelişmenin ekonomik büyümeyi } \\
\text { desteklemediğini belirtmiştir. }\end{array}$ \\
\hline $\begin{array}{l}\text { Bloch ve Tang } \\
(2003)\end{array}$ & $\begin{array}{l}75 \text { ülke } \\
1960-1990\end{array}$ & Panel veri analizi & $\begin{array}{l}\text { Finansal gelişmenin büyümeyi pozitif yönde } \\
\text { etkilediğini belirtmiştir. }\end{array}$ \\
\hline Graff (2003) & $\begin{array}{l}93 \text { ülke } \\
1970-1990\end{array}$ & Panel veri analizi & $\begin{array}{l}\text { Finansal aktivitelerin büyümeyi desteklediğini } \\
\text { belirtmiştir. }\end{array}$ \\
\hline Dawson (2003) & $\begin{array}{l}13 \text { geçiş ekonomisi } \\
1994-1999\end{array}$ & Panel veri analizi & $\begin{array}{l}\text { Finansal gelişmenin büyümeyi önemli ölçüde } \\
\text { etkilemediğini belirtmiştir. }\end{array}$ \\
\hline Atamtürk (2003) & $\begin{array}{l}\text { Türkiye } \\
1975-2003\end{array}$ & $\begin{array}{l}\text { Granger nedensellik } \\
\text { analizi }\end{array}$ & $\begin{array}{l}\text { Nedensellik ilişkisi tek yönlü ve finansal } \\
\text { gelişmeden ekonomik büyümeye doğrudur }\end{array}$ \\
\hline $\begin{array}{l}\text { Bhattacharya } \\
\text { Sivasubramanian } \\
\text { (2003) }\end{array}$ & $\begin{array}{l}\text { Hindistan } \\
1970,1971- \\
1998,1999\end{array}$ & $\begin{array}{l}\text { Johansen eşbütünleşme } \\
\text { ve VECM Granger } \\
\text { nedensellik analizi }\end{array}$ & $\begin{array}{l}\text { Değişkenler arasında eşbütünleşme ilişkisinin } \\
\text { olduğu ve nedenselliğin ise finansal } \\
\text { gelişmeden ekonomik büyümeye doğru } \\
\text { olduğu bulgularına ulaşılmıştır. }\end{array}$ \\
\hline $\begin{array}{l}\text { Calderon ve Liu } \\
\text { (2003) }\end{array}$ & $\begin{array}{l}109 \text { gelişmekte olan } \\
\text { ve endüstrileşmiş } \\
\text { ülke } \\
1960-1994\end{array}$ & $\begin{array}{l}\text { Granger nedensellik } \\
\text { analizi }\end{array}$ & $\begin{array}{l}\text { Hem gelişmiş hem de endüstrileşen ülkelerde } \\
\text { finansal gelişme ile büyüme arasında iki yönlü } \\
\text { nedensellik ilişkisi bulunmuştur. }\end{array}$ \\
\hline $\begin{array}{l}\text { Christopoulos ve } \\
\text { Tsionas (2004) }\end{array}$ & $\begin{array}{l}10 \text { gelişmekte olan } \\
\text { ülke } \\
1970-2000\end{array}$ & $\begin{array}{l}\text { Panel eşbütünleşme, } \\
\text { Panel nedensellik ve } \\
\text { Johansen eşbütünleşme } \\
\text { testi }\end{array}$ & $\begin{array}{l}\text { Çalışma sonucunda finansal derinlik ile } \\
\text { büyüme arasında eşbütünleşme ilişkisi olduğu } \\
\text { belirtilmiş ayrıca finansal derinlikten } \\
\text { büyümeye doğru nedensellik ilişkisinin olduğu } \\
\text { bulgusuna ulaşılmıştır. }\end{array}$ \\
\hline Ergeç (2004) & $\begin{array}{l}\text { Türkiye } \\
\text { 1988Q1-2001Q4 }\end{array}$ & $\begin{array}{l}\text { Granger Nedensellik } \\
\text { Analizi }\end{array}$ & $\begin{array}{l}\text { Kısa dönemde büyümeden finansal gelişmeye } \\
\text { uzun dönemde ise finansal gelişmeden } \\
\text { büyümeye nedensellik olduğunu belirtmiştir. }\end{array}$ \\
\hline $\begin{array}{l}\text { Al-Awad } \\
\text { Harb (2005) }\end{array}$ & $\begin{array}{l}10 \text { Orta doğu ülkesi } \\
1969-2000\end{array}$ & $\begin{array}{l}\text { Panel eşbütünleşme, } \\
\text { Panel Granger } \\
\text { nedensellik, Johansen } \\
\text { eşbütünleşme ve VECM } \\
\text { Granger nedensellik }\end{array}$ & $\begin{array}{l}\text { Panel sonuçlarında finansal gelişme ile } \\
\text { büyüme arasında uzun dönem ilişki } \\
\text { bulunmuştur. Panel nedensellik sonuçlarına } \\
\text { göre büyümeden finansal gelişmeye doğru } \\
\text { tek yönlü nedensellik olduğu sonucuna } \\
\text { varılmıştır. Ayrıca Türkiye için uzun dönemli } \\
\text { ilişki bulunmuş ve büyümeden finansal } \\
\text { gelişmeye doğru tek yönlü nedensellik } \\
\text { bulunmuştur. }\end{array}$ \\
\hline $\begin{array}{l}\text { Abu-Bader ve } \\
\text { Abu-Qarn (2005) }\end{array}$ & $\begin{array}{l}\text { Misır } \\
1960-2001\end{array}$ & $\begin{array}{l}\text { VECM Granger } \\
\text { Nedensellik }\end{array}$ & $\begin{array}{l}\text { Finansal gelişmenin yeni yatırım kaynakları } \\
\text { sağlayarak ve verimlilik artışı kanalı ile uzun } \\
\text { dönemde ekonomik büyümeyi etkilediği } \\
\text { belirtilmiştir. }\end{array}$ \\
\hline $\begin{array}{l}\text { Chang ve Caudill } \\
\text { (2005) }\end{array}$ & $\begin{array}{l}\text { Tayvan } \\
\text { 1962-1998 }\end{array}$ & $\begin{array}{l}\text { VECM Granger } \\
\text { nedensellik }\end{array}$ & $\begin{array}{l}\text { Elde edilen sonuçlar, finansal gelişmeden } \\
\text { büyümeye doğru nedenselliğin olduğunu } \\
\text { göstermektedir. }\end{array}$ \\
\hline
\end{tabular}


Tablo 1. Ampirik Literatür Özeti (Devam)

\begin{tabular}{|c|c|c|c|}
\hline $\begin{array}{l}\text { Habibullah ve } \\
\text { Eng (2006) }\end{array}$ & $\begin{array}{l}\text { Gelişmekte olan } 13 \\
\text { Asya ülkesi } \\
\text { 1990-1998 }\end{array}$ & $\begin{array}{l}\text { GMM ve panel } \\
\text { nedensellik }\end{array}$ & $\begin{array}{l}\text { Nedensellik finansal gelişmeden büyümeye } \\
\text { doğrudur. Ayrıca yazarlar finansal sistem ile } \\
\text { büyüme arasında önemli düzeyde güçlü bir } \\
\text { ilişkinin bulunduğunu ortaya koymuşlardır. }\end{array}$ \\
\hline $\begin{array}{l}\text { Aslan ve Korap } \\
\text { (2006) }\end{array}$ & $\begin{array}{l}\text { Türkiye } \\
\text { 1987Q1-2004Q4 }\end{array}$ & $\begin{array}{l}\text { Johansen eşbütünleşme } \\
\text { ve Granger nedensellik }\end{array}$ & $\begin{array}{l}\text { Finansal gelişme ile büyüme ilişkisinin alınan } \\
\text { değişkenlere göre farklılık gösterdiğini } \\
\text { belirterek, değişkenler arasında uzun dönemli } \\
\text { bir ilişkinin bulunduğu sonucuna varmışlardır. }\end{array}$ \\
\hline $\begin{array}{l}\text { Liang } \\
\text { Jian-Zhou (2006) }\end{array}$ & $\begin{array}{l}\text { Çin } \\
1952-2001\end{array}$ & VAR Analizi & $\begin{array}{l}\text { Finansal gelişme ile büyüme arasında güçlü } \\
\text { bir ilişkinin bulunduğunu belirterek, } \\
\text { büyümeden finansal gelişmeye doğru tek } \\
\text { yönlü nedensellik ilişkisi bulunmuştur. }\end{array}$ \\
\hline Altunç (2008) & $\begin{array}{l}\text { Türkiye } \\
\text { 1970-2006 }\end{array}$ & $\begin{array}{l}\text { Johansen Eşbütünleşme } \\
\text { VECM Granger } \\
\text { nedensellik analizi }\end{array}$ & $\begin{array}{l}\text { Değişkenler arasında eşbütünleşme ilişkisi } \\
\text { bulunmuştur. Nedenselliğin yönünün seçilen } \\
\text { değişkene göre farklılık gösterdiğini belirterek } \\
\text { M2 değişkeni alındığında finansal gelişmeden } \\
\text { ekonomik büyümeye, özel sektör kredilerinin } \\
\text { ve toplam kredilerin GSYH'a oranı alındığı } \\
\text { durumda çift yönlü nedensellik ilişkisi } \\
\text { olduğunu belirtmiştir. }\end{array}$ \\
\hline $\begin{array}{l}\text { Abu-Bader } \\
\text { Abu-Qarn (2008) }\end{array}$ & $\begin{array}{l}\text { Cezayir } \\
1965-2003 \\
\text { Mısır, İsrail, Fas } \\
\text { 1960-2004 } \\
\text { Suriye } \\
\text { 1965-2002 } \\
\text { Tunus } \\
\text { 1961-2004 }\end{array}$ & $\begin{array}{l}\text { Toda-Yamamoto } \\
\text { nedensellik analizi }\end{array}$ & $\begin{array}{l}\text { İsrail dışındaki tüm ülkelerde finansal gelişme } \\
\text { ekonomik büyümeye neden olmaktadır. İsrail } \\
\text { için ise ekonomik büyümeden finansal } \\
\text { gelişmeye doğru nedensellik ilişkisine } \\
\text { rastlanmıştır. }\end{array}$ \\
\hline $\begin{array}{l}\text { Akimov, Wijeweera } \\
\text { ve Dollery (2009) }\end{array}$ & $\begin{array}{l}27 \text { geçiş ekonomisi } \\
1989-2004\end{array}$ & $\begin{array}{l}\text { Dinamik ve statik panel } \\
\text { veri analizi }\end{array}$ & $\begin{array}{l}\text { Geçiş ekonomilerinde, finansal gelişme ve } \\
\text { büyüme arasında güçlü bir iliş̧i olduğunu } \\
\text { belirtmişlerdir. }\end{array}$ \\
\hline $\begin{array}{l}\text { Masih, Al-Elg ve } \\
\text { Madani (2009) }\end{array}$ & $\begin{array}{l}\text { Sudi Arabistan } \\
1985-2004\end{array}$ & $\begin{array}{l}\text { VAR, Johansen } \\
\text { eşbütünleşme ve LRSM } \\
\text { Analizi }\end{array}$ & $\begin{array}{l}\text { Finansal gelişmeden büyümeye doğru } \\
\text { nedensellik ilişkisinin bulunduğu sonucuna } \\
\text { varılmıştır. }\end{array}$ \\
\hline $\begin{array}{l}\text { Jenkins ve } \\
\text { Katırcioglu (2010) }\end{array}$ & $\begin{array}{l}\text { Kıbrıs } \\
1960-2005\end{array}$ & $\begin{array}{l}\text { ARDL sınır testi ve } \\
\text { Granger nedensellik } \\
\text { analizi }\end{array}$ & $\begin{array}{l}\text { Nedensellik ilişkisi tek yönlü olarak finansal } \\
\text { gelişmeden büyümeye doğru elde edilmiştir. }\end{array}$ \\
\hline $\begin{array}{l}\text { Akinlo ve } \\
\text { Egbetunde (2010) }\end{array}$ & $\begin{array}{l}10 \text { Sahra-altı Afrika } \\
\text { ülkesi } \\
1980-2005\end{array}$ & $\begin{array}{l}\text { VECM } \\
\text { Granger nedensellik } \\
\text { analizi }\end{array}$ & $\begin{array}{l}\text { Tüm ülkeler için finansal gelişme ile ekonomik } \\
\text { büyüme arasında eşbütünleşme ilişkisi } \\
\text { olduğunu belirterek, Gabon, Kongo Cmh., } \\
\text { Merkez Afrika Cmh. ve Nijerya için finansal } \\
\text { gelişmeden ekonomik büyümeye, Zambiya } \\
\text { için ekonomik büyümeden finansal gelişmeye, } \\
\text { Kenya, Çad, Güney Afrika, Sierra Leone, } \\
\text { Svaziland için çift yönlü nedensellik ilişkisi } \\
\text { olduğunu ortaya koymuşlardır. }\end{array}$ \\
\hline Akkay (2010) & $\begin{array}{l}\text { Türkiye } \\
\text { 1989Q1-2001Q1 } \\
\text { 2001Q1-2010Q1 }\end{array}$ & Granger nedensellik & $\begin{array}{l}\text { Finansal gelişme ve büyüme ilişkisi iki ayrı } \\
\text { dönem için incelenmiş ve her iki dönemde de } \\
\text { ekonomik büyümeden finansal gelişmeye } \\
\text { doğru tek yönlü nedensellik ilişkisi tespit } \\
\text { edilmiştir. }\end{array}$ \\
\hline Anwar ve Sun (2011) & $\begin{array}{l}\text { Malezya } \\
1970-2007\end{array}$ & $\begin{array}{l}\text { Eşanlı denklem } \\
\text { sistemleri GMM analizi }\end{array}$ & $\begin{array}{l}\text { Finansal gelişmenin yurtiçi sermaye stoku } \\
\text { vasıtasıyla ekonomik büyümeyi etkilediğini } \\
\text { fakat değişkenler arasında doğrudan bir } \\
\text { ilişkinin olmadığı sonucuna varılmıştır. }\end{array}$ \\
\hline $\begin{array}{l}\text { Jalil ve Feridun } \\
\text { (2011) }\end{array}$ & $\begin{array}{l}\text { Pakistan } \\
\text { 1975-2008 }\end{array}$ & ARDL Sınır Testi & $\begin{array}{l}\text { Finansal gelişme ve ekonomik büyüme } \\
\text { arasında güçlü bir ilişkinin bulunduğu } \\
\text { belirlenmiştir. }\end{array}$ \\
\hline
\end{tabular}


Tablo 1. Ampirik Literatür Özeti (Devam)

\begin{tabular}{|c|c|c|c|}
\hline $\begin{array}{l}\text { Kar, Nazlıŏlu ve } \\
\text { Ağır (2011) }\end{array}$ & $\begin{array}{l}15 \text { Orta Doğu ve } \\
\text { Kuzey Afrika ülkesi } \\
1980-2007\end{array}$ & $\begin{array}{l}\text { Konya (2006) } \\
\text { Panel Nedensellik } \\
\text { Analizi }\end{array}$ & $\begin{array}{l}\text { Analize konu olan ülkeler için nedensellik } \\
\text { ilişkisinin değiştiğini belirterek, finansal } \\
\text { gelişme ile ekonomik büyüme arasında kesin } \\
\text { bir iliş̧i olmadığı sonucuna varmışlardır. }\end{array}$ \\
\hline $\begin{array}{l}\text { Djalilov ve Piesse } \\
\text { (2011) }\end{array}$ & $\begin{array}{l}27 \text { geçiş ekonomisi } \\
1992-2008\end{array}$ & $\begin{array}{l}\text { Panel Regresyon ve } \\
\text { Granger nedensellik } \\
\text { analizi }\end{array}$ & $\begin{array}{l}\text { Analiz sonuçları finansal gelişmenin, } \\
\text { büyümenin önemli bir belirleyicisi olduğunu } \\
\text { ortaya koymaktadır. }\end{array}$ \\
\hline Ağayev (2012) & $\begin{array}{l}20 \text { geçiş ekonomisi } \\
1995-2009\end{array}$ & $\begin{array}{l}\text { Panel Eşbütünleşme, } \\
\text { Panel nedensellik }\end{array}$ & $\begin{array}{l}\text { Finansal gelişme ile büyüme arasında uzun } \\
\text { dönem ilişkinin bulunduğu belirtilmiş ve } \\
\text { finansal gelişmeden büyümeye tek yönlü bir } \\
\text { nedensellik ilişkisi olduğunu ortaya } \\
\text { koymuştur. }\end{array}$ \\
\hline Bittencourt (2012) & $\begin{array}{l}4 \text { Latin Amerika } \\
\text { Ülkesi } \\
1980-2007\end{array}$ & Panel veri analizi & $\begin{array}{l}\text { Finansal gelişmenin ekonomik aktivite ve } \\
\text { inovasyon aracılığıyla ekonomik büyümeyi } \\
\text { pozitif yönde etkilediğini belirtmiştir. }\end{array}$ \\
\hline Bojanic (2012) & $\begin{array}{l}\text { Bolivya } \\
1940-2010\end{array}$ & $\begin{array}{l}\text { Johansen eşbütünleşme } \\
\text { ve VECM Granger } \\
\text { nedensellik analizi }\end{array}$ & $\begin{array}{l}\text { Analiz sonuçları finansal gelişme ile büyüme } \\
\text { arasında eşbütünleşme ilişkisinin } \\
\text { bulunduğunu göstermektedir. Ayrıca finansal } \\
\text { gelişmeden büyümeye tek yönlü } \\
\text { nedenselliğin bulunduğu belirlenmiştir. }\end{array}$ \\
\hline $\begin{array}{l}\text { Bozoklu ve Yılancı } \\
(2013)\end{array}$ & $\begin{array}{l}\text { Seçilmiş } 14 \text { ülke } \\
\text { 1988-2011 }\end{array}$ & $\begin{array}{l}\text { Dumitrescu ve Hurlin } \\
\text { (2012) panel Granger } \\
\text { nedensellik analizi }\end{array}$ & $\begin{array}{l}\text { Elde edilen sonuçlar, finansal gelişmeden } \\
\text { büyümeye doğru nedenselliğin olduğunu } \\
\text { göstermektedir. }\end{array}$ \\
\hline $\begin{array}{l}\text { Aydın, Ak, Altunbaş } \\
\text { (2013) }\end{array}$ & $\begin{array}{l}\text { Seçilmiş } 23 \text { ülke } \\
\text { 1991-2009 }\end{array}$ & Panel Regresyon Analizi & $\begin{array}{l}\text { Analiz sonuçlarında finansal gelişmenin } \\
\text { artmasının ekonomik büyümeyi pozitif yönde } \\
\text { etkileyeceği hipotezi reddedilmiştir. }\end{array}$ \\
\hline $\begin{array}{l}\text { Hsueh, Hu ve Tu } \\
\text { (2013) }\end{array}$ & $\begin{array}{l}10 \text { Asya ülkesi } \\
1980-2007\end{array}$ & $\begin{array}{l}\text { Konya (2006) } \\
\text { Panel Nedensellik } \\
\text { Analizi }\end{array}$ & $\begin{array}{l}\text { Elde edilen sonuçlar, finansal gelişmeden } \\
\text { büyümeye doğru nedenselliğin olduğunu } \\
\text { göstermektedir. }\end{array}$ \\
\hline Mutlugün (2014) & $\begin{array}{l}\text { Türkiye } \\
\text { 1988Q1-2012Q4 }\end{array}$ & $\begin{array}{l}\text { VAR Analizi, Granger } \\
\text { nedensellik analizi }\end{array}$ & $\begin{array}{l}\text { Ekonomik büyümeden finansal gelişmeye } \\
\text { nedensellik ilişkisi bulunmuştur. Değişkenler } \\
\text { arasında uzun dönemli bir ilişkinin olmadığı } \\
\text { sonucuna varılmıştır. }\end{array}$ \\
\hline $\begin{array}{l}\text { Aslan ve Yılmaz } \\
(2015)\end{array}$ & $\begin{array}{l}\text { Türkiye } \\
1980-2010\end{array}$ & $\begin{array}{l}\text { Johansen eşbütünleşme } \\
\text { analizi }\end{array}$ & $\begin{array}{l}\text { Finansal gelişme ve büyüme arasında uzun } \\
\text { dönemli bir ilişkinin olduğu tespit edilmiştir. }\end{array}$ \\
\hline $\begin{array}{l}\text { Ak, Altıntaş ve } \\
\text { Şimşek (2016) }\end{array}$ & $\begin{array}{l}\text { Türkiye } \\
\text { 1989-2011 }\end{array}$ & $\begin{array}{l}\text { Toda-Yamamoto } \\
\text { nedensellik analizi }\end{array}$ & $\begin{array}{l}\text { Elde ettikleri finansal gelişme endeksi ile } \\
\text { yaptıkları analizde ekonomik büyümeden } \\
\text { finansal gelişmeye doğru nedensellik ilişkisi } \\
\text { olduğu sonucuna varmışlardır. }\end{array}$ \\
\hline $\begin{array}{l}\text { Contuk ve Güngör } \\
\text { (2016) }\end{array}$ & $\begin{array}{l}\text { Türkiye } \\
\text { 1998Q1-2014Q4 }\end{array}$ & $\begin{array}{l}\text { Granger nedensellik ve } \\
\text { asimetrik nedensellik } \\
\text { analizi }\end{array}$ & $\begin{array}{l}\text { Nedensellik analizi sonuçlarına göre finansal } \\
\text { gelişme ile büyüme arasında iki yönlü } \\
\text { nedensellik olduğu bulgusuna ulaşılmıştır. } \\
\text { Asimetrik nedensellik analizi ise finansal } \\
\text { gelişmeden büyümeye nedensellik ilişkisinin } \\
\text { bulunduğunu ortaya koymuştur. }\end{array}$ \\
\hline $\begin{array}{l}\text { Somun-Kapetanovic } \\
\text { (2016) }\end{array}$ & $\begin{array}{l}94 \text { yüks } \\
1992-2011\end{array}$ & $\begin{array}{l}\text { Panel regresyon ve } \\
\text { GMM analizleri }\end{array}$ & $\begin{array}{l}\text { Yapılan analizlerin tümünde bankacılık } \\
\text { sektörü ve borsanın gelişmesinin ekonomik } \\
\text { büyümeyi pozitif, enflasyon, kamu } \\
\text { harcamaları ve ticari açıklığın negatif } \\
\text { etkilediğini belirtmişlerdir. }\end{array}$ \\
\hline
\end{tabular}

Tablo 1'deki konu ile ilgili seçilmiş literatürdeki çalışmalardaki ortak sonuç finansal gelişme ile ekonomik büyüme arasında uzun dönemli bir ilişkinin olduğu yönündedir. Nedensellik analizleri ise birbirinden farklılık göstermektedir. Bu durumun ülke ya da ülke grubu, dönem ve yöntem farklıklarından kaynaklanıyor olabilir. Fakat bulgulardaki farklılıklar finansal gelişme ile ekonomik büyüme arasında bir nedensellik ilişkisi olduğu gerçeğini değiştirmemektedir. 


\section{Veri Seti ve Analiz}

Bu çalışmada Türkiye için 2006Q1-2018Q2 dönemi üç aylık veriler kullanılmıştır. Finansal gelişme göstergesi olarak özel sektör kredilerinin GSYH'a oranı (osk) toplam yurtiçi kredilerin GSYH'a oranı ( $t k$ ), M1 ve M2 parasal büyüklüklerin GSYH'a oranı ve ekonomik büyümeyi temsilen de reel GSYH'ın yüzde değişimi (gdp) kullanılmıştır. Üç aylık zaman periyodunu içeren serilerde mevsimsel etkiler olabileceğinden tüm seriler TRAMO/SEATS yöntemi ile mevsimsel etkilerden arındırılmıştır. Çalışmada kullanılan veriler T.C. Merkez Bankası EVDS'den alınmıştır. M1 paranın ödeme işlevini ve M2 paranın tasarruf fonksiyonunu göstermektedir. Bu parasal büyüklükler ekonomik aktiviteye bağlı olarak değişim göstermektedir. Böylece finansal sistemin büyüklüğü hakkında bilgi sahibi olunabilmektedir (Kar vd., 2011:688). Khan ve Senhadji (2003) yurtiçi kredilerin GSYH'a oranının finansal gelişmişliği temsil eden iyi bir gösterge olduğunu belirtmiştir. Odedokun (1989) ile Liang ve Teng (2006) çalışmalarında toplam yurtiçi kredilerin GSYH'a oranının finans alanında faaliyet gösteren firmaların toplam iç varlıklarını temsil ettiği için finansal gelişme değişkeni olarak kullanılabileceğini belirtmişlerdir. Özel sektör kredileri ise finansal aracılık hizmetlerinin boyutunu belirlemede önemli bir değişken olarak kullanılabilmektedir.

\subsection{Birim Kök Testi}

Birim kök sürecinin özelliği bir şokun uzun kalıcı etkiye sahip olmasıdır. Çalışmada ele alınan değişkenlere ADF birim kök testi uygulanmıştır. ADF birim kök testinde Denklem (1), (2) ve (3) tahmin edilmektedir;

$$
\begin{aligned}
& \Delta Y_{t}=\delta Y_{t-1}+\sum_{i=1}^{m} \alpha_{i} \Delta Y_{t-i}+u_{t} \\
& \Delta Y_{t}=\beta_{1}+\delta Y_{t-1}+\sum_{i=1}^{m} \alpha_{i} \Delta Y_{t-i}+u_{t} \\
& \Delta Y_{t}=\beta_{1}+\beta_{2} t+\delta Y_{t-1}+\sum_{i=1}^{m} \alpha_{i} \Delta Y_{t-i}+u_{t}
\end{aligned}
$$

Serinin birim köke sahip olduğunu ifade eden sıfır hipotezi $H_{0}: \delta=0$ olarak ifade edilmektedir. $H_{0}$ hipotezinin reddedilmesi durumunda ele alınan serinin durağan olduğuna karar verilir. Değişkenlerin

\begin{tabular}{|c|c|c|c|c|}
\hline \multirow{2}{*}{ Değişken } & \multirow{2}{*}{ ADF Test İstatistikleri } & \multicolumn{3}{|c|}{ Kritik Değerler } \\
\hline & & (\%1) & $(\% 5)$ & (\%10) \\
\hline$g d p$ & $-3.258[4]^{* *}$ & -3.584 & -2.928 & -2.602 \\
\hline$\Delta g d p$ & $-4.459[9]^{*}$ & -3.610 & -2.938 & -2.607 \\
\hline osk & $-1.142[0]$ & -3.571 & -2.922 & -2.599 \\
\hline$\Delta o s k$ & $-5.800[0]^{*}$ & -3.574 & -2.923 & -2.599 \\
\hline$t k$ & $-1.100[1]$ & -3.574 & -2.923 & -2.599 \\
\hline$\Delta t k$ & $-8.723[0]^{*}$ & -3.574 & -2.923 & -2.599 \\
\hline M1 & $-0.898[8]$ & -3.600 & -2.935 & -2.605 \\
\hline$\Delta M 1$ & $-4.119[7]^{*}$ & -3.600 & -2.935 & -2.605 \\
\hline M2 & $-2.256[0]$ & -3.571 & -2.922 & -2.599 \\
\hline$\Delta M 2$ & $-3.458[7]^{* *}$ & -3.577 & -2.925 & -2.600 \\
\hline
\end{tabular}
bütünleşik derecelerini belirlemek için ADF testi uygulanmış ve elde edilen sonuçlar Tablo 4 'de sunulmuştur.

Tablo 2. ADF Birim Kök Testi Sonuçları

Not: Köşeli parantez içindeki sayılar, değişkenlerin AIC (Akaike Bilgi Kriteri)'ye göre belirlenmiş uygun gecikme uzunluklarını göstermektedir. *, ** ve *** sırasıyla; $\% 1, \% 5$ ve $\% 10$ düzeyinde anlamlılığı göstermektedir. 
Tablo 4'de incelendiğinde analizde kullanılan gdp değişkeninin durağan olduğu, diğer değişkenlerin ise durağan olmayıp birinci farklarında durağan hale geldikleri sonucuna ulaşılmıştır.

\subsection{Nedensellik Analizi}

Granger'in (1969) nedensellik testlerinin kullanımı zaman serisi verilerinin kullanıldığı ampirik çalışmalarda giderek artmaktadır. Toda ve Yamamoto (1995), serilerin farklı bütünleşme derecelerine izin veren bir yaklaşım ortaya koymuşlardır. Hacker ve Hatemi-J (2006) ise Toda ve Yamamoto (1995) prosedürünü takip etmiş ve kritik değerlerin elde edilmesinde bootstrap yaklaşımı kullanılmasının daha iyi sonuç verdiğini göstermişlerdir. Toda-Yamamoto prosedürü gecikmesi artırılmış VAR modeline dayanmaktadır. $\operatorname{VAR}(p)$ modeli Denklem (4) ile verilebilir:

$$
y_{t}=v+A_{1} y_{t-1}+\cdots+A_{p} y_{t-p}+\varepsilon_{t}
$$

Burada $y_{t}, v$ ve $\varepsilon_{t}$ n-boyutlu vektörler ve $A_{r}$ ise $r$ gecikme için parametrelerin bir $n \times n$ matrisidir. Toda ve Yamamoto (1995), bütünleşik değişkenler arasındaki nedenselliği test edebilmek için kullanılabilecek genelleştirilmiş $\operatorname{VAR}(p+d)$ modelini önermiştir:

$$
y_{t}=\hat{v}+\hat{A}_{1} y_{t-1}+\cdots+\hat{A}_{p} y_{t-p}+\cdots+\hat{A}_{p+d} y_{t-p-d}+\hat{\varepsilon}_{t}
$$

Burada sürecin $p$ gecikme uzunluğunun bilindiği varsayılmakta ve $d$ ise değişkenlerin maksimum bütünleşme derecelerini göstermektedir. Eğer $H_{0}$ hipotezi reddedilemez ise $y_{t}{ }^{\prime}$ nin $k$. elemanı, $y_{t}{ }^{\prime}$ nin $j$. elemanının Granger nedeni olmadığı ifade edilmektedir (Hacker ve Hatemi-J, 2006: 1491);

$$
H_{0}: \mathrm{r}=1, \ldots, \mathrm{p} \text { için } A_{r} \text { matrisindeki } j \text {. satır } k \text {. sütündaki eleman sı fıra eşittir }
$$

Örnek büyüklüğü $T$ için,

$Y:=\left(y_{1}, \ldots, y_{T}\right), \operatorname{bir}(n \times T)$ boyutlu matris,

$\widehat{D}:=\left(\hat{v}, \hat{A}_{1}, \ldots, \hat{A}_{p}, \ldots, \hat{A}_{p+d}\right), \operatorname{bir}(n \times(1+n(p+d)))$ boyutlu matris,

$Z_{t}:=\left[\begin{array}{c}1 \\ y_{t} \\ y_{t-1} \\ \vdots \\ y_{t-p-d+1}\end{array}\right], \operatorname{bir}((1+n(p+d)) \times 1)$ boyutlu matris, $t=1, \ldots, T$ için

$Z:=\left(Z_{0}, \ldots, Z_{T-1}\right)$, bir $((1+n(p+d)) \times T)$ boyutlu matris ve

$\hat{\delta}:=\left(\hat{\varepsilon}_{1}, \ldots, \hat{\varepsilon}_{T}\right), \operatorname{bir}(n \times T)$ boyutlu matristir.

Bu notasyon kullanılarak, sabit terim $(\hat{v})$ içeren $\operatorname{VAR}(p+d)$ modeli Denklem (6) ile yazılabilir;

$$
Y=\widehat{D} Z+\hat{\delta}
$$

Burada, $\hat{\delta}_{U},(6)$ numaralı kısıtsız regresyondan elde edilen kalıntılar olmak üzere varyans-kovaryans matrisi $S_{U}=\hat{\delta}_{U}^{\prime} \hat{\delta}_{U} / T$ şeklinde tanımlanır. vec (column-stacking) opertör ve $0_{n \times n d}, n$ satırlı ve $n(d)$ sütunlu sıfır matrisini temsil etmek üzere $\beta=\operatorname{vec}\left(v, A_{1}, \ldots, A_{p}, 0_{n \times n d}\right)$ ve $\hat{\beta}=\operatorname{vec}(\widehat{D})$ olarak tanımlanabilir. Toda ve Yamamoto (1995) tarafından önerilen modifiye edilmiş Wald (MWALD) istatistiği Denklem (7)'de verilmiştir:

$$
M W A L D=(C \hat{\beta})^{\prime}\left[C\left(\left(Z^{\prime} Z\right)^{-1} \oplus S_{U}\right) C^{\prime}\right]^{-1}(C \hat{\beta})
$$


Burada $\oplus$ Kronecker çarpımı ve $C$ ise $\operatorname{pxn}(1+n(p+d))$ boyutlu matristir. Granger nedensellik ilişkisinin olmadığını ifade eden sıfır hipotezi $H_{0}: C \hat{\beta}=0$ şeklindedir. MWALD test istatistiği, $p^{\prime}$ ye eşit serbestlik derecesi sayısı ve test edilecek kısıtlamaların sayısı ile asimptotik olarak $\chi^{2}$ dağılmaktadır. Hacker ve Hatemi-J (2006), MWALD testinin boyut özelliklerini araştırdığı çalışmalarında küçük örneklerde ki-kare dağılımı kullanıldığında test performansının zayıf olduğunu ileri sürmüşlerdir. Hacker ve Hatemi-J (2006), boyut bozulmalarını azaltmak için bootstrap dağıımının kullanılmasını önermişlerdir. Çalışmanın Monte Carlo simülasyon sonuçları, bootstrap dağılımına dayalı MWALD testinin, asimptotik dağıımın kullanıldığı durumlardan daha küçük boyut bozulmalara sahip olduğunu göstermektedir. Hacker ve Hatemi-J (2006) yaklaşımında, tahmin edilen VAR modeli ile gecikme uzunluğu dışsal olarak belirlenmektedir. Hacker ve Hatemi-J (2012) tarafından önerilen bootstrap nedensellik testinde ise Hacker ve Hatemi-J (2006)'den farklı olarak gecikme uzunluğunun içsel olarak belirlendiği durumlar araştırıımıştır.

Literatürde yer alan bütün nedensellik testleri seçilen gecikme uzunluğuna dayanmakta ve gecikme uzunluğu seçimi sonuçları etkileyebilmektedir. Bu bağlamda uygun gecikme uzunluğunun belirlenmesi oldukça önemli bir konudur. Literatürde, uygun gecikme uzunluğunu belirlemek için çeşitli bilgi kriterleri kullanılmakta ve bu kriterler bazen farklı gecikme uzunlukları seçebilmektedir. Hatemi-J $(2003,2008)$, uygun gecikme uzunluğu seçimi için Schwarz (1978) ile Hannan ve Quinn (1979) bilgi kriterlerinin birleştirilmesi ile elde edilen bir bilgi kriteri önermiştir. Bu çalışmada da uygun gecikme uzunluğu, Hatemi-J $(2003,2008)$ tarafından önerilen ve aşağıda verilen bilgi kriterinin minimizasyonu ile belirlenmiştir.

$$
H J C=\ln \left(\operatorname{det} \widehat{\Omega}_{j}\right)+j\left(\frac{n^{2} \ln T+2 n^{2} \ln (\ln T)}{2 T}\right), \quad j=0,1, \ldots, p
$$

Burada det $\widehat{\Omega}_{j}$, VAR (j) modelindeki kalıntıların tahmin edilen maksimum olabilirlik varyanskovaryans matrisinin determinantını temsil etmektedir. Değişkenlerin sayısı $n$ ile ifade edilmekte ve $T$ örnek büyüklüğünü In ise doğal logaritmayı göstermektedir (Hatemi-J ve Uddin, 2014: 377). Hacker ve Hatemi-J (2012) tarafından önerilen bootstrap nedensellik testi sonuçları Tablo 5'te sunulmuştur.

Tablo 3. Hacker ve Hatemi-J (2012) Bootstrap Nedensellik Testi Sonuçları

\begin{tabular}{|c|c|c|c|c|c|}
\hline & \multirow{2}{*}{$\operatorname{Var}(p)$} & \multirow{2}{*}{ MWALD Test İstatistiği } & \multicolumn{3}{|c|}{ Bootstrap Kritik Değerleri } \\
\hline & & & $\% 1$ & $\% 5$ & $\% 10$ \\
\hline$o s k=>g d p$ & 1 & 0.089 & 7.992 & 4.174 & 2.836 \\
\hline$g d p=>$ osk & 1 & 1.002 & 8.019 & 4.131 & 2.824 \\
\hline$t k=>g d p$ & 1 & $4.084^{* *}$ & 7.237 & 3.984 & 2.805 \\
\hline$g d p=>t k$ & 1 & 2.760 & 7.345 & 4.174 & 2.795 \\
\hline$M 1=>g d p$ & 2 & 0.772 & 10.758 & 6.808 & 5.134 \\
\hline$g d p=>M 1$ & 2 & 3.849 & 10.011 & 6.436 & 4.822 \\
\hline$M 2=>g d p$ & 1 & 0.247 & 7.067 & 4.056 & 2.794 \\
\hline$g d p=>M 2$ & 1 & 1.644 & 7.293 & 4.051 & 2.847 \\
\hline
\end{tabular}

Not: Uygun gecikme uzunluğu HJC Bilgi kriterine göre belirlenmiştir. Bootstrap kritik değerleri 10.000 döngüyle elde edilmiştir. 
Tablo 5 incelendiğinde $t k$ değişkeninden $g d p$ değişkenine nedensellik ilişkisini gösteren MWALD test istatistiği, bootstrap yöntemi ile elde edilen kritik değerden büyük olduğundan sıfır hipotezi reddedilmektedir. Buna göre $t k$ değişkeninden $g d p$ değişkenine doğru nedensellik ilişkisinin olduğu sonucuna ulaşılmıştır. Bu sonuç Patrick (1966) tarafından önerilen finansal sistemi oluşturan tüm bileşenlerin yatırımcıların talepleri doğrultusunda ortaya çıktığını belirten arz öncüllü hipotezin geçerliliğini ortaya koymaktadır.

\section{Sonuç}

Küreselleşme ve teknolojik yeniliklerin etkisi ile finansal sistem hem yatırım hem de tasarruf sahipleri açısından daha cazip bir hale gelmiştir. Finansal sistem üzerindeki bu olumlu etki ekonomik aktivitede bir artışa neden olmaktadır. Ayrıca devletin bankacılık sistemi üzerindeki kısıtlamalarının finansal gelişmeyi olumsuz etkileyerek ekonomik büyümeyi düşüreceği yönünde de görüşler vardır. Ekonomik işlemlerde meydana gelen artış ekonomik büyüme üzerinde pozitif anlamda bir etki meydana getirmektedir. Literatürde bu önermenin tersi durumunu yani ekonomik büyümenin finansal gelişmeyi etkilediği yönünde de birçok yaklaşım yer almaktadır.

Literatürde finansal gelişme ekonomik büyüme ilişkisini inceleyen teorik ve ampirik çalışmaların birçoğu içsel büyüme modellerinin de etkisi ile finansal gelişme ile ekonomik büyüme arasında bir ilişki olduğunu ortaya koymakta fakat ilişkinin yönü konusunda bir genelleme yapılamamaktadır. Çünkü çalışmalar örneklem, dönem ve zaman boyutu bakımından farklılık göstermektedir.

Bu çalışmada finansal gelişme ile büyüme arasındaki nedensellik ilişkisi literatürde genel kabul görmüş finansal gelişmişlik göstergeleri kullanılarak incelenmiştir. Analize konu olan özel sektör kredilerinin GSYH'ya oranı, M1 ve M2 parasal büyüklüklerinin GSYH'a oranı ve toplam yurtiçi kredilerin GSYH'a oranı değişkenlerinden sadece toplam yurtiçi kredilerin GSYH'a oranından ekonomik büyümeye doğru nedensellik ilişkisi elde edilmiştir. Bu sonuç Türkiye ekonomisinde finansal gelişmenin kredi kanalı ile büyümeyi etkilediğini göstermektedir. Ayrıca elde edilen sonuçlar Patrick (1966) tarafından ileri sürülen arz-öncüllü gelişim hipotezini desteklemektedir.

\section{Son Notlar}

* Bu çalışma, 28-29-30 Kasım 2018 tarihlerinde düzenlenen "IV. International Conference on Applied Economics and Finance \& Extended with Social Sciences (ICOAEF'18)" kongresinde sözlü olarak sunulmuş ve öz kısmı Bildiri Özetleri Kitabında yayınlanmıştır.

\section{Kaynaklar}

Abu-Bader, S., \& Abu-Qarn, A. (2005). Financial development and economic growth: Time series evidence from Egypt. Monaster Center for Economic Research, Discussion Paper No. 05-14a, Ben-Gurion University of the Negev, Israel.

Abu-Bader, S., \& Abu-Qarn, A. S. (2008). Financial development and economic growth: Empirical evidence from six MENA countries. Review of Development Economics, 12(4), 803-817.

Ağayev, S. (2012). Geçiş ekonomilerinde finansal gelişme ve ekonomik büyüme ilişkisi. Muğla Üniversitesi iktisadi ve idari Bilimler Dergisi, 32(1), 155-164.

Ak, M. Z., Altıntaş, N., \& Şimşek, A. S. (2016). Türkiye'de finansal gelişme ve ekonomik büyüme ilişkisinin nedensellik analizi. Doğuş Üniversitesi Dergisi, 17(2), 151-160.

Akimov, A., Wijeweera, A., \& Dollery, B. (2009). Financial development and economic growth: Evidence from transition economies. Applied Financial Economics, 19(12), 999-1008.

Akinboade, O. A. (1998). Financial development and economic growth in Botswana: A test for causality. Savings and Development, 22(3), 331-348. 
Akinlo, A. E., \& Egbetunde, T. (2010). Financial development and economic growth: The experience of 10 Sub-Saharan African countries revisited. The Review of Finance and Banking, 2(1), 17-28.

Akkay, C. (2010). Finansal entegrasyon sürecinde finansal gelişme ekonomik büyüme arasındaki nedenselliğin Türkiye açısından dönemsel olarak araştırılması. Sosyal Bilimler Dergisi, (2), 55-70.

Al-Awad, M., \& Harb, N. (2005). Financial development and economic growth in the Middle East. Applied Financial Economics, 15(15), 1041-1051.

Altunç, Ö. F. (2008). Türkiye'de finansal gelişme ve iktisadi büyüme arasındaki nedenselliğin ampirik bir analizi. Eskişehir Osmangazi Üniversitesi iiBF Dergisi, 3(2), 113-127.

Anwar, S., \& Sun, S. (2011). Financial development, foreign investment and economic growth in Malaysia. Journal of Asian Economics, 22(4), 335-342.

Arestis, P., \& Demetriades, P. (1997). Financial development and economic growth: Assessing the evidence. The Economic Journal, 107(442), 783-799.

Aslan, N., \& Yılmaz, O. (2015). Finansal gelişme ve büyüme ilişkisinin Solow modeli ile analizi: Türkiye üzerine bir çalışma. Finansal Araştırmalar ve Çalışmalar Dergisi, 7(12), 17-39.

Aslan, Ö., \& Korap, H. L. (2011). Türkiye'de finansal gelişme ekonomik büyüme ilişkisi. Sosyal ve Beşeri Bilimler Araştırmaları Dergisi, (17), 1-20.

Atamtürk, B. (2004). Türkiye'de finansal gelişme ve ekonomik büyümenin nedensellik yönü üzerine bir inceleme (19752003). Maliye Araştırma Merkezi Konferansları, (46), 99-105.

Aydın, M. K., Ak, M. Z., \& Altuntaş, N. (2013). 'Çevre' ülkelerinde finansal gelişme ile büyüme arasındaki ilişki: Panel veri analizi. Hacettepe Üniversitesi İktisadi ve Idari Bilimler Fakültesi Dergisi, 31(2), 1-14.

Bhattacharya, P. C., \& Sivasubramanian, M. N. (2003). Financial development and economic growth in India: 1970-1971 to 1998-1999. Applied Financial Economics, 13(12), 925-929.

Bittencourt, M. (2012). Financial development and economic growth in Latin America: Is Schumpeter right? Journal of Policy Modeling, 34(3), 341-355.

Bloch, H., \& Tang, S. H. K. (2003). The role of financial development in economic growth. Progress in Development Studies, 3(3), 243-251.

Bojanic, A. N. (2012). The Impact of financial development and trade on the economic growth of Bolivia. Journal of Applied Economics, 15(1), 51-70.

Bozoklu, Ş., \& Yılancı, V. (2013). Finansal gelişme ve iktisadi büyüme arasındaki nedensellik ilişkisi: Gelişmekte olan ekonomiler için analiz. Dokuz Eylül Üniversitesi Iktisadi ve Idari Bilimler Fakültesi Dergisi, 28(2), 161-187.

Calderón, C., \& Liu, L. (2003). The direction of causality between financial development and economic growth. Journal of Development Economics, 72(1), 321-334.

Chang, T., \& Caudill, S. B. (2005). Financial development and economic growth: The case of Taiwan. Applied Economics, 37(12), 1329-1335.

Christopoulos, D. K., \& Tsionas, E. G. (2004). Financial development and economic growth: Evidence from panel unit root and cointegration tests. Journal of Development Economics, 73(1), 55-74.

Contuk, F. Y., \& Güngör, B. (2016). Asimetrik nedensellik testi ile finansal gelişme ekonomik büyüme ilişkisinin analizi. Muhasebe ve Finansman Dergisi, (71), 89-108.

Dawson, P. J. (2003). Financial development and growth in economies in transition. Applied Economics Letters, 10(13), 833-836.

Demetriades, P. O., \& Hussein, K. A. (1996). Does financial development cause economic growth? Time-series evidence from 16 countries. Journal of Development Economics, 51(2), 387-411.

Demetriades, P. O., \& Luintel, K. B. (1996). Financial development, economic growth and banking sector controls: Evidence from India. The Economic Journal, 106(435), 359-374.

Djalilov, K., \& Piesse, J. (2011). Financial development and growth in transition countries: A study of Central Asia. Emerging Markets Finance and Trade, 47(6), 4-23.

Somun-Kapetanovic, R., Resic, E., \& Satrovic, E. (2016). Panel analysis of relationship between financial development and economic growth. In 8th International Conference of the School of Economics and Business (Vol. 48, p. 247). University of Sarajevo, School of Economics and Business Trg oslobodjenja-Alija Izetbegovic 1, Sarajevo, Bosnia and Herzegovina. 
Ergeç, E. H. (2004). Finansal gelişme ile ekonomik büyüme arasındaki nedensellik ilişkisi ve Türkiye örneği: 19882001. Eskişehir Osmangazi Üniversitesi Sosyal Bilimler Dergisi, 5(2), 51-66.

Fung, M. K. (2009). Financial development and economic growth: Convergence or divergence? Journal of International Money and Finance, 28(1), 56-67.

Ghali, K. H. (1999). Financial development and economic growth: The Tunisian experience. Review of Development Economics, 3(3), 310-322.

Graff, M. (2003). Financial development and economic growth in corporatist and liberal market economies. Emerging Markets Finance and Trade, 39(2), 47-69.

Granger, C. W. J. (1969). Investigating causal relations by econometric models and cross-spectral methods. Econometrica, 37(3), 424-438.

Habibullah, M. S., \& Eng, Y. K. (2006). Does financial development cause economic growth? A panel data dynamic analysis for the Asian developing countries. Journal of the Asia Pacific Economy, 11(4), 377-393.

Hacker, R. S., \& Hatemi-J, A. (2006). Tests for causality between integrated variables using asymptotic and bootstrap distributions: Theory and application. Applied Economics, 38(13), 1489-1500.

Hacker, S., \& Hatemi-J, A. (2012). A bootstrap test for causality with endogenous lag length choice: Theory and application in finance. Journal of Economic Studies, 39(2), 144-160.

Hatemi-J, A., \& Uddin, G. S. (2014). On the causal nexus of remittances and poverty reduction in Bangladesh. Applied Economics, 46(4), 374-382.

Hatemi-J, A. (2003). A new method to choose optimal lag order in stable and unstable VAR models. Applied Economics Letters, 10(3), 135-137.

Hatemi-J, A. (2008). Forecasting properties of a new method to determine optimal lag order in stable and unstable VAR models. Applied Economics Letters, 15(4), 239-243.

Hsueh, S. J., Hu, Y. H., \& Tu, C. H. (2013). Economic growth and financial development in Asian countries: A bootstrap panel granger causality analysis. Economic Modelling, 32, 294-301.

Jalil, A., \& Feridun, M. (2011). Impact of financial development on economic growth: Empirical evidence from Pakistan. Journal of the Asia Pacific Economy, 16(1), 71-80.

Jenkins, H. P., \& Katırcıoglu, S. T. (2010). The bounds test approach for cointegration and causality between financial development, international trade and economic growth: The case of Cyprus. Applied Economics, 42(13), 16991707.

Kar, M., Nazlığlu, Ş., \& Ağır, H. (2011). Financial development and economic growth nexus in the MENA countries: Bootstrap panel granger causality analysis. Economic Modelling, 28(1-2), 685-693.

Khan, M. S., Senhadji, A. S. (2003). Financial development and economic growth: A review and new evidence. Journal of African Economies, 12(supp_2), ii89-ii110.

Levine, R. (1999). Financial development and economic growth: Views and agenda. The World Bank. https://elibrary.worldbank.org/doi/abs/10.1596/1813-9450-1678\#

Liang, Q., \& Jian-Zhou, T. (2006). Financial development and economic growth: Evidence from China. China Economic Review, 17(4), 395-411.

Masih, M., Al-Elg, A., \& Madani, H. (2009). Causality between financial development and economic growth: An application of vector error correction and variance decomposition methods to Saudi Arabia. Applied Economics, 41(13), 1691-1699.

Mutlugün, B. (2014). The relationship between financial development and economic growth for Turkey. iktisat Politikası Araştırmaları Dergisi, 1(2), 85-115.

Odedokun, M. O. (1989). Causalities between financial aggregates and economic activities in Nigeria: The results from Granger's rest. Savings and Development, 23(1), 101-111.

Öztürk, N., Darıcı, H. K., \& Kesikoğlu, F. (2011). Ekonomik büyüme ve finansal gelişme ilişkisi: gelişmekte olan piyasalar için bir panel nedensellik analizi. Marmara Üniversitesi Iktisadi ve Idari Bilimler Dergisi, 30(1), 53-69.

Patrick, H. T. (1966). Financial development and economic growth in underdeveloped countries. Economic development and Cultural Change, 14(2), 174-189.

Ram, R. (1999). Financial development and economic growth: Additional evidence. The Journal of Development Studies, 35(4), 164-174.

Robinson, J. (1952). The rate of interest and other essays. London: Macmillan. 
Toda, H. Y., \& Yamamoto, T. (1995). Statistical inference in vector autoregressions with possibly integrated processes. Journal of Econometrics, 66(1), 225-250.

Wooldridge, J. M. (2013). Ekonometriye Giriş Modern Yaklaşım. Çev. Editörü: E. Çağlayan. Nobel Akademik Yayıncılık. 